\title{
Том \\ Neglected spaces in science communication
}

\section{Clare Wilkinson}

\begin{abstract}
Many of the earliest drivers for improved scientific literacy and understanding were based on the assumption that science and technology is all around us, and yet there are some spaces and communities that are neglected in science communication contexts. In this brief comment, Clare Wilkinson introduces a series of ten commentaries, which further probe neglected spaces in science communication.
\end{abstract}

Keywords

Public engagement with science and technology; Public perception of science and technology; Social inclusion

DOI

https://doi.org/10.22323/2.20010301

Submitted: 2nd December 2020

Accepted: 2nd December 2020

Published: 1st February 2021

Many of the earliest drivers for improved scientific literacy and understanding were based on the assumption that science and technology is all around us. This ethos that science is part of our world, is also apparent in countless communication efforts today and is a clear justification for broad public inclusion in research engagement, and yet as science communicators and science communication researchers, it is often easy to focus on the most popular subject matter, or activities and events which generate the greatest obvious attention. As a community, we therefore know a huge amount about subjects such as immunisation, GM, nuclear power and other timely topics, as well as the activities of the mass media, and science centres and museums. We perhaps focus less on the equally important but less visible spaces and subjects in which science communication can be happening in peoples' daily lives.

This series of commentaries emerged from an idea to focus on the ways in which people might encounter science communication beyond its most typical settings. Areas such as public health, the arts, protest, emerging digital spaces, and the boundaries between science and education. I was also keen to explore the intersections between "traditional" spaces and activities for science communication and other areas of interest. However, little did I know, when developing this idea, that we were about to face one of the most acute science communication challenges of a generation. A global pandemic, which would bring us together in many ways, and yet also heighten our inequalities in others. 
Neglect is a powerful concept. In its more discreet forms it can simply mean something has been overlooked; to forget do something, or to fail to recall, or to be unable to picture something, and what that might look like. However, neglect can also have more significant ramifications. It can involve neglecting people for whom we may have responsibilities. To neglect to care or to understand. It can also mean we neglect to give attention to things that are important and cause harm. In this series of commentaries there are examples which traverse both settings for neglect, conscious and unconscious, negligent and overlooked, as well as the potent reasons why such spaces are so important to consider.

In the first commentary, Summer Finlay, Sujatha Raman, Elizabeth Rasekoala, Vanessa Mignan, Emily Dawson, Liz Neeley and Lindy Orthia take us on a journey from the margins to the mainstream, powerfully arguing that cultural narrowness and ambient racism has led science communication to neglect to recognise, value and learn with a diversity of nations and communities. Next, Hessam Habibi Doroh and Barbara Streicher, discuss their efforts in Knowledge ${ }^{\circ}$ Room, pop-up science engagement, which takes place in disused shops. They discuss how their project strives for social justice by working with the local Afghan and Iranian migrant community and encouraging science communicators to consider socio-cultural relevance when planning activities and events. In a similar spirit, Wyn Griffiths and Lindsay Keith, introduce SMASHfestUK, a science, technology, engineering, arts, mathematics and medicine festival working with marginalised communities. Their commentary situates quotes and comments from collaborators at its heart, and illustrates how they have sought to co-design with their collaborating communities, creating a new model for inclusive engagement.

Tara Roberson and Lindy Orthia highlight the neglected space of queer people in science communication. Introducing queer theory to science communication literature, they insightfully argue that queering science communication entails more than recognising that queer people are present in science communication. Next, Helen Bayram and Karen Ironside, present a practical example in the case of STEMroller, a roller derby which creates a space for women and genderqueer people to be themselves, whilst using sport and a social environment, as a tool to empower and inspire a different view of those working in science, technology, engineering and maths careers. The social element continues in the next commentary, authored by Hannah Little and I, on the role of escape rooms in science communication. We explore how escape rooms as a recent cultural phenomena can be used to attract a range of people to science communication, but also create a versatile new space for communication, engagement and involvement. Next, Maria Elena Villar, discusses her work in health and social issues, and explains how storytelling through fotonovelas, radio stories, community drama and serious games, have all been utilised in working with immigrant communities in Miami, Florida to co-create community engagement with science.

Finally, the three concluding commentaries explore more specific subjects which might be neglected in science communication contexts. Ana Claudia Nepote and Pedro Medina-Rosas introduce the conundrum of marine science in Mexico. Despite the significant marine environment that surrounds Mexico, and its importance for tourism, they discuss the challenges of making it locally relevant and the ways in which they are seeking to enhance cultural, social and economic connections. Aarti Kapoor and Merryn McKinnon next discuss a neglected medical 
intervention, hysterectomy. In their commentary they explain how women's health conditions are often 'taboo topics' and the role that science communication might play in shared medical decision-making. And last but by no means least, Robert O'Malley, John Slattery, Curtis Baxter, and Katy Hinman, examine science engagement with faith. In their commentary, the authors introduce principles for science engagement with faith communities, which can enhance public perceptions and trust in scientists, as well as diversity, equity and inclusion in science fields.

As the editor for this series of commentaries, I am conscious of the stories and examples that are still missing from this series. I am also mindful of the differing cultural and social contexts in which some commentaries will be set and how these may or may not align to readers situated in differing environments and perspectives. There remain voices that are absent; inevitably requesting commentaries at a time when COVID-19 was placing increased caring responsibilities, illness, worries and workload on many, creates its challenges. I am therefore extremely grateful to all authors who took the time to provide their commentaries, and hopeful this set of commentaries is just a starting point, and continues a multitude of conversations, ownership and agency for such narratives, and further attention on neglected spaces in science communication, to continue in the future.

Author

Dr. Clare Wilkinson, is an Associate Professor in Science Communication and Co-Director of the Science Communication Unit (SCU) at UWE, Bristol. The main focus of Clare's research is public engagement, including how different disciplines, researchers and public participants are mobilised to engage. Her work has been published in a wide range of journals including New Media and Society, Science Communication, Journalism Practice, Health, Risk \& Society, and Public Understanding of Science. In 2016 Clare co-authored the book Creative Research Communication: Theory and Practice with Emma Weitkamp, and published by Manchester University Press. She is the series editor for Contemporary Issues in Science Communication, published by Bristol University Press.

E-mail: clare.wilkinson@uwe.ac.uk.

How to cite

Wilkinson, C. (2021). 'Neglected spaces in science communication'. JCOM 20 (01), C01. https:/ / doi.org/10.22323/2.20010301. 